\title{
Influence of progesterone supplementation during the first third of pregnancy on fetal and placental growth in overnourished adolescent ewes
}

\author{
J. M. Wallace, D. A. Bourke, P. Da Silva and R. P. Aitken \\ Rowett Research Institute, Bucksburn, Aberdeen AB21 9SB, UK
}

\begin{abstract}
Overnourishing adolescent ewes throughout pregnancy promotes maternal tissue synthesis at the expense of placental growth, which in turn leads to a major decrease in lamb birth weight. As maternal dietary intakes are inversely related to peripheral progesterone concentrations in these adolescent dams, it was hypothesized that supoptimal progesterone concentrations in overnourished dams may compromise the growth of the differentiating conceptus resulting in fewer uterine caruncles being occupied and, hence, fewer placentomes formed. This hypothesis was tested by supplementing overnourished adolescent dams with exogenous progesterone during early pregnancy and determining the impact on pregnancy outcome at term. Embryos recovered from superovulated adult ewes inseminated by a single sire were transferred in singleton to the uterus of peripubertal adolescent recipients. After transfer of embryos, ewes were offered a moderate or high amount of a complete diet ( $n=11$ per group). A further high intake group received a progesterone supplement each day from day 5 to day 55 of gestation (term= 145 days) to restore circulating progesterone concentrations to moderate values throughout the first third of pregnancy $(n=11)$. For ewes establishing pregnancies
\end{abstract}

( $n=7$ per group), live weight gain during the first 100 days of gestation was $66 \pm 4,323 \pm 17$ and $300 \pm 7 \mathrm{~g}$ per day, body condition score at term was $2.1 \pm 0.05,3.0 \pm 0.08$ and $3.1 \pm 0.07$ units and the duration of gestation after spontaneous delivery was $148 \pm 1.7,144 \pm 0.8$ and $143 \pm$ 0.8 days for the moderate intake, high intake and high intake plus progesterone groups, respectively. At delivery, fetal cotyledon mass $(136 \pm 12.1$ versus $57 \pm 8.2 \mathrm{~g}$, $P<0.001)$ and lamb birth weight $(5164 \pm 151$ versus $2893 \pm 381 \mathrm{~g}, P<0.001)$ were higher in moderate intake than in high intake dams. Progesterone supplementation restored circulating concentrations to moderate values during the first third of gestation. Lamb birth weight in the high intake plus progesterone group $(4150 \pm 389 \mathrm{~g})$ was intermediate between the high intake $(P<0.02)$ and moderate intake $(P<0.05)$ groups, but this change in birth weight was not associated with corresponding changes in fetal cotyledon mass $(76 \pm 10.3 \mathrm{~g})$. Moreover, the number of fetal cotyledons was similar in all three groups. Thus, progesterone did not directly affect the growth of the fetal cotyledon but may have influenced placental vascularity, blood flow or nutrient transfer capacity or alternatively the development of the embryonic inner cell mass.

\section{Introduction}

Human adolescent mothers have an increased risk of preterm delivery of low birth weight babies compared with women aged $>20$ years (McAnarney, 1987). As $50 \%$ of human adolescents continue to grow while pregnant (Scholl et al., 1997), a highly controlled animal paradigm has been developed to examine the role of maternal nutrition and growth status on the aetiology of poor pregnancy outcome. In this paradigm, it has been consistently demonstrated that overnourishing singleton bearing adolescent sheep promotes rapid maternal growth (primarily of adipose tissue) throughout pregnancy at the expense of the nutrient requirements

Email: jacqueline.wallace@rri.sari.ac.uk of the gravid uterus. This overnourishing results in a major reduction in placental mass and a significant decrease in lamb birth weight at term relative to slow growing moderate intake, adolescent dams of equivalent gynaecological age (Wallace et al., 1996, 1997a). The profound decrease in placental mass at term in the overnourished adolescent dams reflects a significant reduction in both the number of fetal cotyledons per placenta and mean fetal cotyledon mass (Wallace et al., 2001). The former observation implies that the underlying mechanism may be an early pregnancy event as the number of uterine caruncles occupied by the developing trophoblast is determined by day 50 of gestation (Barcroft and Kennedy, 1939; Wallace, 1948).

Low progesterone concentrations are a characteristic feature of high dietary intakes in both adult and adolescent sheep (Wallace et al., 1994, 1997b) and progesterone 
plays a major role in controlling the maternal secretion of nutrients, growth factors and immunosuppressive agents required for successful embryo development and pregnancy recognition (Spencer and Bazer, 2002). Thus, it was hypothesized in the present study that sub-optimal progesterone concentrations in the overnourished dams may compromise the growth of the differentiating conceptus and result in fewer uterine caruncles being occupied during early pregnancy and consequently fewer placentomes developing and being maintained during pregnancy. The aim of the present study was to test this hypothesis by supplementing overnourished adolescent dams with exogenous progesterone during early pregnancy and to determine the impact on the duration of gestation, placental mass and lamb birth weight at term. As placental mass and lactogenic hormone concentrations have been shown to be closely correlated with the initial colostrum production in these adolescent animals (Wallace et al., 1997a, 2001) the effect of diet and early pregnancy progesterone supplementation on colostrum yield immediately after parturition was also assessed.

\section{Materials and Methods}

\section{Animals and experimental design}

Embryos from superovulated adult ewes (Border Leicester $\times$ Scottish Blackface), inseminated by a single sire, were recovered on day 4 after oestrus and transferred singularly into the uterus of 33 synchronized recipient ewe lambs (Dorset Horn $\times$ Mule) exactly as described by Wallace et al. (1997a). Embryo transfer was carried out during the mid-breeding season and the animals were housed in individual pens under natural lighting conditions at the Rowett Research Institute $\left(57^{\prime} \mathrm{N}, 2^{\prime} \mathrm{W}\right)$. At the time of embryo transfer, the recipient ewe lambs were peripubertal ( 7 months old) and had a mean live weight of $46 \pm 0.4 \mathrm{~kg}$. Immediately after embryo transfer, recipient ewe lambs were allocated evenly to one of three treatments on the basis of live weight, body condition score and ovulation rate at the time of transfer. Where possible, care was also taken to randomize for embryo source. Two groups of recipients were individually offered either a moderate $(n=11)$ or high $(n=11)$ amount of a complete diet calculated to promote normal or rapid maternal growth rates, respectively. A third group of high intake ewes received in addition $12.5 \mathrm{mg}$ progesterone each day $(1 \mathrm{ml})$ from day 5 to day 55 of gestation (high plus progesterone, $n=11$ ). This dose of progesterone was used as it had been found to restore circulating concentrations of progesterone in overfed non-pregnant adolescent ewes to those of maintenance intake ewes (control concentrations) when administered each day for a period of 5 days during the luteal phase of the oestrous cycle (J. M. Wallace, unpublished). Progesterone (Progesterone
Injectable, Intervet UK Ltd, Cambridge) was administered i.m. at 10:00 h each day. The complete diet supplied $10.2 \mathrm{MJ}$ metabolizable energy and $137 \mathrm{~g}$ crude protein per $\mathrm{kg}$ and was offered in two equal feeds at 08:00 h and 16:00 h each day. The diet contained $30.0 \%(\mathrm{w} / \mathrm{w})$ coarsely-milled hay, $50.0 \%$ barley, $10.0 \%$ molasses, $9.0 \%$ fishmeal, $0.3 \%$ salt, $0.5 \%$ dicalcium phosphate and $0.2 \%$ of a vitamin-mineral supplement and had an average dry matter of $86 \%$. Animals offered moderate intake diets received their entire ration immediately after embryo transfer, whereas for dams offered high intake diets the amount of feed was gradually increased over 2 weeks until the amount of daily feed refusal was approximately $15 \%$ of the total amount offered (equivalent to ad libitum intakes). The amount of feed offered was reviewed three times each week and adjusted, on an individual basis as and when appropriate, on the basis of body weight change data (recorded weekly) and the amount of feed refused (recorded daily). After day 100 of gestation the feed intake of the moderate intake group was adjusted each week to maintain body condition score and, hence, meet the increasing nutrient demands of the developing fetus during the final third of pregnancy. The moderate intake group was in fact a control group in that this intake amount was predicted to optimize fetal growth for this genotype (Wallace et al., 2001). Body condition score was assessed on a five point scale ( $1=$ emaciated, $5=$ obese; Russel et al., 1969).

\section{Measurements}

Blood samples were collected by jugular venepuncture at 10:00 h, three times a week (Monday, Wednesday and Friday) throughout gestation and analysed for progesterone. In the progesterone-supplemented group, blood samples were collected immediately before progesterone administration. Plasma progesterone concentrations were measured directly in duplicate, as described by Ronayne and Hynes (1990). The limit of detection was $0.2 \mathrm{ng} \mathrm{ml}^{-1}$ and the intra- and interassay coefficients of variation were 8.5 and $10.6 \%$, respectively.

Pregnancy outcome was determined after spontaneous vaginal delivery at term. All ewes were supervised throughout the delivery period. Immediately after parturition, the lamb was dried and its body weight, abdominal girth and crown-rump length recorded. Immediately after the fetal portion of the placenta was spontaneously delivered, it was blotted, weighed and laid out on a tray to confirm that the entire fetal placenta had been shed. Fetal cotyledons were dissected from the fetal membranes and counted, and their total weight was recorded. Oxytocin was administered i.v. to induce milk let-down (Oxytocins, 6 iu per ewe; Intervet Ltd) and the ewe was milked by hand until all the available colostrum was stripped from the udder to facilitate determination of colostrum yield before the first suckling episode and within $30 \mathrm{~min}$ of parturition. Colostrum yield was determined by weighing 
Table 1. Changes in maternal live weight and body condition score in ewes offered a moderate $(M)$ or high $(H)$ nutrient intake throughout pregnancy and in a further high intake group that received progesterone each day from day 5 to day 55 of gestation $(\mathrm{H}+$ progesterone $)$

\begin{tabular}{|c|c|c|c|c|c|c|}
\hline & \multirow{2}{*}{\multicolumn{3}{|c|}{ Maternal dietary intake }} & \multicolumn{3}{|c|}{ Significance } \\
\hline & & & & \multirow[b]{2}{*}{$M$ versus $\mathrm{H}$} & \multirow{2}{*}{$\begin{array}{l}\mathrm{M} \text { versus } \mathrm{H}+ \\
\text { progesterone }\end{array}$} & \multirow{2}{*}{$\begin{array}{l}\mathrm{H} \text { versus } \mathrm{H}+ \\
\text { progesterone }\end{array}$} \\
\hline & M & $\mathrm{H}$ & $\mathrm{H}+$ progesterone & & & \\
\hline \multicolumn{7}{|l|}{ Live weight $(\mathrm{kg})$ at } \\
\hline Embryo transfer & $47.7 \pm 1.10$ & $44.6 \pm 0.67$ & $45.5 \pm 0.51$ & $P<0.02$ & ns & ns \\
\hline Day 56 & $50.9 \pm 0.99$ & $62.3 \pm 1.05$ & $61.7 \pm 1.06$ & $P<0.001$ & $P<0.001$ & ns \\
\hline Day 100 & $54.0 \pm 0.96$ & $75.6 \pm 1.62$ & $74.3 \pm 0.74$ & $P<0.001$ & $P<0.001$ & ns \\
\hline Day 140 & $69.1 \pm 0.88$ & $86.5 \pm 1.95$ & $86.0 \pm 0.95$ & $P<0.001$ & $P<0.001$ & ns \\
\hline \multicolumn{7}{|l|}{ Body condition score at } \\
\hline Embryo transfer & $2.2 \pm 0.07$ & $2.1 \pm 0.05$ & $2.1 \pm 0.05$ & ns & ns & ns \\
\hline Day 100 & $2.1 \pm 0.05$ & $2.8 \pm 0.08$ & $2.8 \pm 0.04$ & $P<0.001$ & $P<0.001$ & ns \\
\hline Day 140 & $2.1 \pm 0.05$ & $3.0 \pm 0.08$ & $3.1 \pm 0.07$ & $P<0.001$ & $P<0.001$ & ns \\
\hline \multicolumn{7}{|l|}{ Live weight gain } \\
\hline Days 5-100 (g per day) & $66 \pm 4$ & $323 \pm 17$ & $300 \pm 7$ & $P<0.001$ & $P<0.001$ & ns \\
\hline
\end{tabular}

Values are mean \pm SEM.

$n=7$ per group.

ns: not significant.

and the colostrum was then administered to the lamb at $50 \mathrm{ml}$ per kg body weight.

\section{Statistical analysis}

Data are presented as means \pm SEM. For the pregnancy outcome data, differences between treatments were analysed by ANOVA and specific treatment comparisons were then analysed by $t$ test on the basis of pooled standard deviations. A similar approach was used to analyse the progesterone data after calculating a mean individual progesterone value spanning the supplementation period (from day 7 to day 54), the second third of pregnancy (from day 56 to day 97) and the final third of pregnancy (from day 100 to day 139). Correlation analysis was by Pearson's product moment test and a Kruskal-Wallis test was used to confirm that the ovulation rate of the recipient ewes which conceived was not significantly different between groups.

\section{Results}

Maternal dietary intakes, weight and body condition score

Seven ewes per group became pregnant after embryo transfer and spontaneously delivered live lambs at term. For these ewes, the dry matter feed intakes are shown (Fig. 1) and the diet-induced changes in maternal weight and body condition score during pregnancy are shown (Table 1). Mean maternal dietary intakes were markedly increased in ad libitum (high) compared with moderate intake ewes throughout gestation $(P<0.001)$. Dietary intakes in the high compared with the high intake plus progesterone groups were equivalent during the period of exogenous progesterone treatment (from day 5 to day

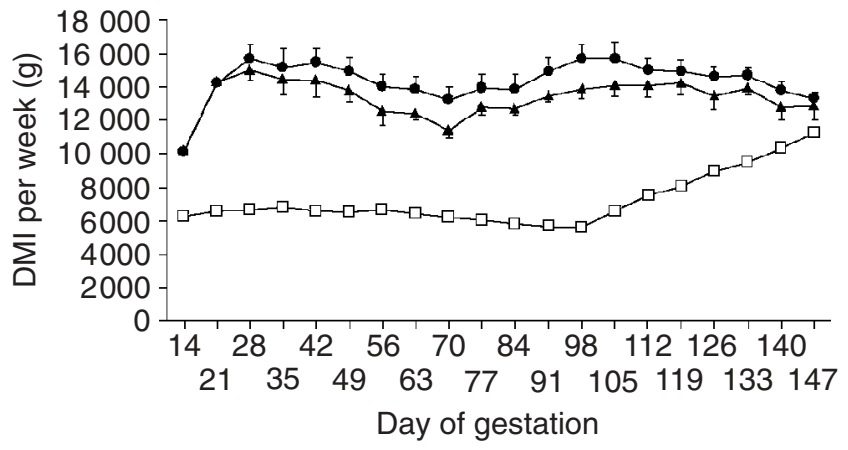

Fig. 1. Weekly dry matter intake (DMI) throughout pregnancy in singleton-bearing adolescent dams offered a moderate $(\square)$ or high (-) nutrient intake. A further high intake group received progesterone each day from day 5 to 55 of gestation $(\mathbf{\Lambda})$. Values are mean \pm SEM; $n=7$ per group.

55 of gestation) and increased slightly thereafter in the high intake group $(P<0.05)$. Maternal live weight and body condition score were significantly increased in both ad libitum fed groups relative to the moderate intake (control) group by the end of the first third of pregnancy and remained higher throughout the study. Progesterone supplementation per se did not influence live weight or body condition score at any of the time points measured and similarly live weight gain during the first 100 days of gestation was equivalent in the high intake and high intake plus progesterone groups.

\section{Maternal progesterone concentrations}

For the ewes that conceived, mean ovulation rates at embryo transfer were $2.4 \pm 0.3,2.3 \pm 0.4$ and $1.6 \pm 0.2$ corpora lutea for the moderate intake, high intake and 
Table 2. Maternal plasma progesterone concentrations $\left(\mathrm{ng} \mathrm{ml}^{-1}\right)$ throughout gestation in ewes offered a moderate $(\mathrm{M})$ or high $(\mathrm{H})$ nutrient intake throughout pregnancy and in a further high intake group that received progesterone each day from day 5 to day 55 of gestation $(\mathrm{H}+$ progesterone $)$

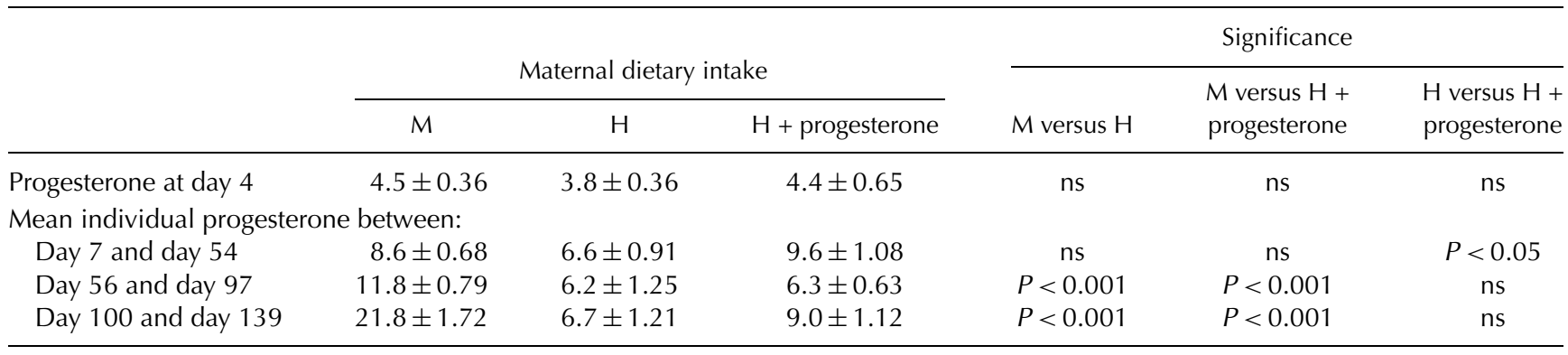

Mean data calculated from plasma progesterone concentrations measured three times each week.

Values are mean \pm SEM.

$n=7$ per group.

ns: not significant.

high intake plus progesterone groups, respectively, and was not significantly different among groups. Mean plasma progesterone concentrations were equivalent at embryo transfer on day 4 of the oestrous cycle (Table 2). Circulating progesterone concentrations determined from blood samples taken three times each week immediately before the time of the routine daily progesterone injection were highly variable (Fig. 2). Nevertheless, average mean individual progesterone concentrations in the high intake group were lower than in the moderate intake and high intake plus progesterone groups (Table 2). This trend reached significance $(P<0.05)$ when the high intake and high intake plus progesterone groups were compared. Thus, circulating progesterone concentrations were largely restored to moderate (or control) values during the period of exogenous supplementation. Thereafter, progesterone concentrations immediately decreased to the concentrations observed in the high intake group (Fig. 2). During the second two thirds of gestation, mean progesterone concentrations were similar in high intake and high intake plus progesterone groups and significantly lower $(P<0.001)$ than in the moderate intake group.

\section{Pregnancy outcome}

The gestational age at delivery and morphometric data relating to pregnancy outcome are shown (Table 3). The duration of gestation was shorter in both the high intake $(P<0.05)$ and high intake plus progesterone $(P<0.01)$ groups relative to the moderate intake control group. Total fetal placental mass $(P<0.01)$, fetal cotyledon mass $(P<0.001)$ and lamb birth weight $(P<0.001)$ were lower in the high intake compared with the moderate intake group. Lamb birth weight in the high intake plus progesterone group was intermediate between the high intake $(P<0.02)$ and moderate intake $(P<0.05)$ groups but this change in birth weight was not associated

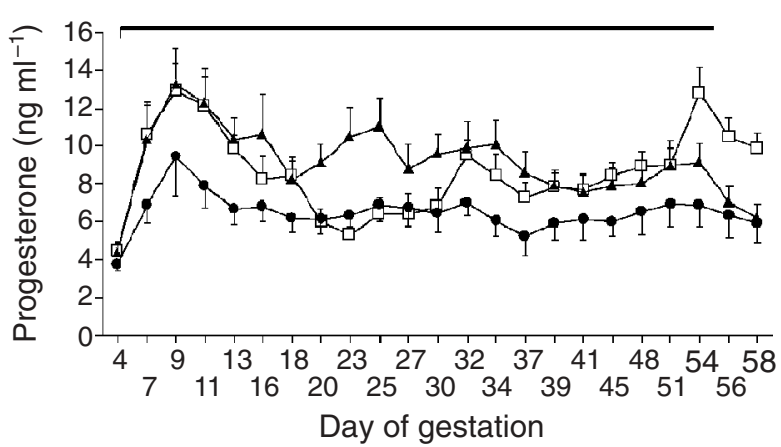

Fig. 2. Maternal peripheral plasma progesterone concentrations determined three times each week during the first 58 days of pregnancy in singleton-bearing adolescent dams offered a moderate $(\square)$ or high $(\mathbf{O})$ nutrient intake. A further high intake group received progesterone each day from day 5 to 55 of gestation $(\mathbf{\Delta})$. The period of progesterone supplementation is indicated by the solid bar. Samples were withdrawn immediately before progesterone administration at 10:00 h. Values are mean $\pm S E M$; $n=7$ per group.

with an alteration in either total placental or cotyledon masses (Table 3). The fetal:placental weight ratio was increased in the high intake plus progesterone group but this trend did not reach significance. The number of fetal cotyledons per placenta was not influenced by the treatment group. One pregnancy in the high intake group was extremely unusual in that the placenta had 256 fetal cotyledons and a total fetal cotyledon mass of only $38 \mathrm{~g}$. The lamb, which was born on day 143 of gestation, weighed $1540 \mathrm{~g}$ at birth but died within $2 \mathrm{~h}$ of delivery. The range of numbers of fetal cotyledons at term for this genotype in control ewes is 78-108 (Wallace et al., 2001). Calculation of the average fetal cotyledon mass per placenta with this unusual animal excluded resulted in a mean \pm SEM of $0.76 \pm 0.10 \mathrm{~g}$ for the high intake group, which remained significantly different from the 
Table 3. Morphometric data relating to pregnancy outcome in ewes offered a moderate $(M)$ or high $(H)$ nutrient intake throughout pregnancy and in a further high intake group that received progesterone each day from day 5 to day 55 of gestation $(\mathrm{H}+$ progesterone)

\begin{tabular}{|c|c|c|c|c|c|c|}
\hline & \multirow{2}{*}{\multicolumn{3}{|c|}{ Maternal dietary intake }} & \multicolumn{3}{|c|}{ Significance } \\
\hline & & & & \multirow[b]{2}{*}{$M$ versus $H$} & \multirow{2}{*}{$\begin{array}{l}\mathrm{M} \text { versus } \mathrm{H}+ \\
\text { progesterone }\end{array}$} & \multirow{2}{*}{$\begin{array}{l}\mathrm{H} \text { versus } \mathrm{H}+ \\
\text { progesterone }\end{array}$} \\
\hline & M & $\mathrm{H}^{*}$ & $\mathrm{H}+$ progesterone & & & \\
\hline Gestation duration (days) & $148.0 \pm 1.70$ & $144.3 \pm 0.80$ & $142.9 \pm 0.83$ & $P<0.05$ & $P<0.01$ & $\mathrm{~ns}$ \\
\hline Lamb birth weight (g) & $5164 \pm 151$ & $2893 \pm 381$ & $4150 \pm 389$ & $P<0.001$ & $P<0.05$ & $P<0.02$ \\
\hline Fetal placental mass (g) & $498 \pm 18.9$ & $294 \pm 57.2$ & $318 \pm 41.5$ & $P<0.01$ & $P<0.01$ & ns \\
\hline Number of fetal cotyledon & $85 \pm 6.9$ & $111 \pm 30.1$ & $76 \pm 12.6$ & ns & ns & ns \\
\hline Total fetal cotyledon mass (g) & $136 \pm 12.1$ & $57 \pm 8.2$ & $76 \pm 10.3$ & $P<0.001$ & $P<0.001$ & ns \\
\hline Fetal:placental mass ratio & $10.6 \pm 0.65$ & $10.9 \pm 1.61$ & $13.1 \pm 1.87$ & ns & $\mathrm{ns}$ & $\mathrm{ns}$ \\
\hline $\begin{array}{l}\text { Mean fetal cotyledon mass } \\
\text { per placenta }(\mathrm{g})\end{array}$ & $1.62 \pm 0.117$ & $0.66 \pm 0.135$ & $1.06 \pm 0.124$ & $P<0.001$ & $P<0.01$ & $P<0.05$ \\
\hline $\begin{array}{l}\text { Colostrum yield at } \\
\text { parturition }(\mathrm{ml})\end{array}$ & $398 \pm 78.2$ & $93 \pm 30.9$ & $182 \pm 58.5$ & $P<0.002$ & $P<0.02$ & $\mathrm{~ns}$ \\
\hline
\end{tabular}

*Includes one outlier with respect to cotyledon number (256 cotyledons).

Values are mean \pm SEM.

$n=7$ per group.

ns: not significant.

moderate intake group $(P<0.001)$ but was no longer significantly different from the high intake plus progesterone group. The calculation of the average number of cotyledons with the unusual animal excluded resulted in a mean \pm SEM of $83 \pm 10.4$ and did not impact on the lack of statistical difference in the number of cotyledons among the three groups. Colostrum yield, measured within 30 min of parturition, was significantly lower in both the high intake $(P<0.002)$ and high intake plus progesterone $(P<0.02)$ groups relative to the moderate intake group.

Within the two high intake groups $(n=14)$ there was no significant correlation between maternal live weight gain during the first 100 days of pregnancy and the duration of gestation $(r=-0.287)$, placental mass $(r=-0.248)$ or lamb birth weight $(r=-0.482)$.

\section{Discussion}

The present study confirms previous observations that high dietary intakes promoting rapid maternal growth rates throughout pregnancy in adolescent sheep result in significant placental and fetal growth restriction (Wallace et al., 1996, 1997a, 2001). Progesterone supplementation of high intake dams successfully restored circulating progesterone concentrations to moderate values during the first third of gestation and enhanced lamb birth weight, which was intermediate between the high and moderate intake groups. However, this significant change in lamb birth weight was not associated with a corresponding change in total fetal placental mass or cotyledon mass and number as originally hypothesized. These results do not preclude the possibility of subtle effects of progesterone on placental function or on the growth of the maternal caruncular portion of the placentome but they do raise the additional possibility of an effect of progesterone on the differentiating embryonic inner cell mass. A two- to threefold increase in circulating progesterone concentrations during the first 6 days of pregnancy in sheep has been shown to enhance fetal growth, as determined at days 74-76 of gestation (Kleemann et al., 1994, 2001). A similar increase in circulating progesterone concentrations in cattle during days 1-4 of the oestrous cycle produced qualitative alterations in endometrial protein secretion and advanced conceptus development at day 14 of pregnancy (Garrett et al., 1988). In the present study, although progesterone supplementation did not begin until day 5 of pregnancy, after transfer of morula stage embryos on day 4 of the oestrous cycle into the tip of the uterine horn, it still resulted in enhanced lamb birth weight. This progesterone supplementation from day 5 onwards could have influenced the secretory profile of the uterus to provide a nutritive environment (nutrients, growth factors) which was similar to that of the moderate intake (control) group. Alternatively, progesterone treatment may have influenced blastocyst differentiation directly (for example, by influencing the genes involved in acquiring polarity). Progesterone administration during the first few days of pregnancy in sheep has been reported to result in a preferential allocation of cells to the trophoblast compared with the inner cell mass (Hartwich et al., 1995) and also results in earlier trophoblast elongation. However, as progesterone supplementation in the present study resulted in enhanced fetal growth with no significant change in placental mass or the number of placentomes, the opposite effect is implied. Similarly, the enhanced fetal growth reported by Kleemann et al. (2001) after progesterone administration during the first few days of 
pregnancy was independent of changes in placental mass (Kleemann et al., 2001). Indeed, other fetal overgrowth syndromes, some of which may involve progesteronemediated effects, have not been associated with larger placentae (Young et al., 1998). Further support for the concept that progesterone may have been influencing the inner cell mass during the first days of treatment in the present study (either directly or via alterations in the uterine histotroph nourishing the embryo) comes from a similar unpublished study in which progesterone supplementation of rapidly growing adolescent dams was delayed until day 11 of pregnancy. At this point allocation of blastomeres into trophectoderm versus inner cell mass lineages is complete and hence progesterone was administered between day 11 and day 55 of gestation. In this study lamb birth weight and fetal placental mass at term were low and equivalent in both high intake $(n=9)$ and high intake plus progesterone $(n=6)$ groups relative to the moderate intake control $(n=9)$ group, (birth weights $3166 \pm 360,3246 \pm 476$ and $5178 \pm 152 \mathrm{~g}$, and placental masses $283 \pm 21,240 \pm 31$ and $449 \pm 36 \mathrm{~g}$, respectively, in the high intake, high intake plus progesterone and moderate intake groups; J. M. Wallace, D. A. Bourke and R. P. Aitken, unpublished).

In the adolescent sheep paradigm, irrespective of nutritional treatment group, placental mass accounts for over $70 \%$ of the variability in fetal weight (Wallace et al., 2001). Furthermore, in late gestation, the reductions in uterine and umbilical blood flows, nutrient uptakes and glucose transport in overnourished dams are all directly in proportion to the degree of placental growth restriction observed (Wallace et al., 2002a,b). However, it is also possible that progesterone supplementation of the overnourished dams during early pregnancy impacted on placental vascularity, blood flow or nutrient transfer capacity independently of alterations in placental mass. When administered in pharmacological doses, progesterone will induce overgrowth of the uterine caruncles (Alexander and Williams, 1966) and growth of uterine blood vessels (Caton et al., 1974) in ovariectomized sheep. In physiological doses, the administration of progesterone to ewes during a very short window of development, namely days 1-3 of pregnancy, increased placental volumes of chorionic membrane and maternal crypts and, hence, the surface area for nutrient exchange, independent of changes in placental mass per se (Kleemann et al., 2001). Similar mechanisms may underlie the beneficial effects of exogenous progesterone on fetal nutrient supply in this study.

Using this experimental paradigm, it has been reported that overfeeding to promote rapid maternal growth throughout pregnancy results in a modest but highly significant reduction in placentome number both in pregnancies terminated in late gestation (Wallace et al., 2002a) and after spontaneous delivery at term (Wallace et al., 1996, 1997a, 1999, 2001). As outlined in the introduction, these findings implied that overfeeding the adolescent sheep in this way had a detrimental effect on initial maternal caruncle occupancy - an early pregnancy event. However, in the present study, the number of placentomes was unaffected by maternal nutrition or progesterone supplementation. This lack of effect may simply be due to the lower than normal conception rate in all three groups after embryo transfer (64 versus $75 \%$ ) and, hence, the relatively small numbers of animals studied compared with earlier work. However, in adolescent dams studied recently at day 80 of gestation, no differences in the number of placentomes in high compared with moderate dietary intake groups were detected $(99 \pm 6.3$ versus $104 \pm 4.8$ placentomes, respectively, $n=14$ per group; J. M. Wallace, unpublished). This finding indicates that a normal number of caruncles are originally occupied but fewer continue to develop to their full size and transport potential during the second half of pregnancy in the overnourished group. Indeed, the major reduction in uteroplacental blood flows observed at day 130 of gestation in overnourished adolescent dams (Wallace et al., 2002a) may be sufficient to induce atrophy or regression of a proportion of placentomes during the second half of pregnancy.

In the present study, pregnancy rates were equivalent in all three groups. Numerous studies using the highly controlled adolescent sheep paradigm have failed to detect a consistent effect of high dietary intakes during early pregnancy on conception rates after embryo transfer (Wallace et al., 2001). In contrast, in adult sheep, pregnancy rates were reduced in ewes offered a high compared with a medium or low feed intake between day 2 and day 14 after mating, and pregnancy rates were completely restored when the animals were treated with physiological doses of progesterone during the same period (Parr et al., 1987).

Although, in the present study, progesterone supplementation in the high intake group from day 5 to 55 of pregnancy significantly enhanced fetal growth relative to the non-supplemented high intake group, the duration of gestation in the two groups was equivalent and lower than in the moderate intake animals. The precise endocrine changes underlying premature parturition in the overnourished adolescent have not been defined but may be initiated by nutritionally induced alterations in placental hormone secretion during the final weeks of pregnancy. Similarly, colostrum yield at parturition was low in both high intake groups and unaffected by early pregnancy progesterone supplementation. This finding supports earlier observations that impaired placental mass at term and attenuated lactogenic hormone secretion in the second half of pregnancy $(\mathrm{GH}$, placental lactogen and progesterone) are closely associated with a major reduction in colostrum yield immediately after parturition in the overnourished adolescent paradigm (Wallace et al., 1997a, 2001). Similarly, human adolescents who breastfeed have significantly less breast milk 
volume compared with mature breastfeeding mothers, indicating that the hierarchy of nutrient partitioning is compromised during lactation as well as pregnancy in adolescents (Motil et al., 1997).

In conclusion, the present study supports the hypothesis that sub-optimal progesterone concentrations in the overnourished dams may compromise the growth of the differentiating conceptus but does not support the initial suggestion that this may be manifest by lower caruncle occupancy during pregnancy.

The authors thank M. Cruickshank for skilled technical assistance, G. Horgan (BIOSS) for statistical advice and the Scottish Executive Environment and Rural Affairs Department for financial support.

\section{References}

Alexander G and Williams D (1966) Progesterone and placental development in the sheep Journal of Endocrinology 34 241-245

Barcroft J and Kennedy JA (1939) The distribution of blood flow between the foetus and the placenta in sheep Journal of Physiology, London 95 173-186

Caton D, Abrams RM, Clapp JF and Barron DH (1974) The effect of exogenous progesterone on the rate of blood flow of the uterus of ovariectomised sheep Quarterly Journal of Experimental Physiology $\mathbf{5 9}$ 225-231

Garrett JE, Geisert RD, Zavy MT and Morgan GL (1988) Evidence for maternal regulation of early conceptus growth and development in beef cattle Journal of Reproduction and Fertility 84 437-446

Hartwich KM, Walker SK, Owens JA and Seamark RF (1995) Progesterone supplementation in the ewe alters cell allocation to the inner cell mass Proceedings of the Australian Society of Medical Research 26128 (Abstract)

Kleemann DO, Walker SK and Seamark RF (1994) Enhanced fetal growth in sheep administered progesterone during the first three days of pregnancy Journal of Reproduction and Fertility 102 411-417

Kleemann DO, Walker SK, Hartwich KM, Fong Lok, Seamark RF, Robinson JS and Owens JA (2001) Fetoplacental growth in sheep administered progesterone during the first three days of pregnancy Placenta 22 14-23

McAnarney ER (1987) Young maternal age and adverse neonatal outcome American Journal of Diseases of Children 141 1053-1059

Motil KJ, Kertz B, Thotath U and Chery M (1997) Lactational performance of adolescent mothers shows preliminary difference from that of adult women Journal of Adolescent Health 20 442-446

Parr RA, Davis IF, Fairclough RJ and Miles MA (1987) Overfeeding during early pregnancy reduces peripheral progesterone concentration and pregnancy rate in sheep Journal of Reproduction and Fertility $\mathbf{8 0}$ $317-320$
Ronayne E and Hynes N (1990) Measurement of plasma progesterone concentrations by extraction and non-extraction radioimmunoassays Irish Journal of Agricultural Research 29 109-115

Russel AJF, Doney JM and Gunn RG (1969) Subjective assessment of body fat in live sheep Journal of Agricultural Science, Cambridge $\mathbf{7 2}$ 451-454

Scholl TO, Hediger ML and Schall JI (1997) Maternal growth and fetal growth: pregnancy course and outcome in the Camden study Annals of the New York Academy of Science 81 292-301

Spencer TE and Bazer FW (2002) Biology of progesterone action during pregnancy recognition and maintenance of pregnancy Frontiers in Bioscience 7 D1879-D1898

Wallace JM, Aitken RP and Cheyne MA (1994) Effect of post-ovulation nutritional status in ewes on early conceptus survival and growth in vivo and luteotrophic protein secretion in vitro. Reproduction, Fertility and Development 6 253-259

Wallace JM, Aitken RP and Cheyne MA (1996) Nutrient partitioning and fetal growth in rapidly growing adolescent ewes Journal of Reproduction and Fertility 107 183-190

Wallace JM, Da Silva P, Aitken RP and Cheyne MA (1997a) Maternal endocrine status in relation to pregnancy outcome in rapidly growing adolescent sheep Journal of Endocrinology 155 359-368

Wallace JM, Aitken RP, Cheyne MA and Humblot P (1997b) Pregnancyspecific protein $\mathrm{B}$ and progesterone concentrations in relation to nutritional regimen, placental mass and pregnancy outcome in growing adolescent ewes carrying singleton fetuses Journal of Reproduction and Fertility 109 53-58

Wallace JM, Bourke DA, Aitken RP and Cruickshank MA (1999) Switching maternal dietary intake at the end of the first trimester has profound effects on placental development and foetal growth in adolescent ewes carrying singleton fetuses Biology of Reproduction 61 101-110

Wallace JM, Bourke DA, Da Silva P and Aitken RP (2001) Nutrient partitioning during adolescent pregnancy Reproduction 122 347-357

Wallace JM, Bourke DA, Aitken RP, Leitch N and Hay WW, Jr (2002a) Blood flows and nutrient uptakes in growth-restricted pregnancies induced by overnourishing adolescent sheep American Journal of Physiology Regulatory Integrative and Comparative Physiology 282 R1027-R1036

Wallace JM, Bourke DA, Aitken RP, Milne JS and Hay WW, Jr (2002b) Placental glucose transport in growth-restricted pregnancies induced by overnourishing adolescent sheep Journal of Physiology 547 85-94

Wallace LR (1948) The growth of lambs before and after birth in relation to the level of nutrition Journal of Agricultural Science 38 243-300

Young LE, Sinclair KD and Wilmut I (1998) Large offspring syndrome in cattle and sheep Reviews of Reproduction 3 155-163

Received 27 May 2003.

First decision 1 July 2003

Revised manuscript received 3 July 2003

Accepted 7 July 2003. 